\title{
Robotic System for Employment of People with Disabilities
}

\author{
Zhumadil Baigunchekov*, Zhadyra Zhumasheva, BekzaAmanov, ErnaZholdasov, Berik Sagitzhanov and Alibek \\ Tleukhanov
}

Al-Farabi Kazakh National University, Kazakhstan

*Corresponding author: ZhumadilBaigunchekov, Scientific Educational Centre "Digital Technologies and Robotics", Al- Farabi Kazakh National University, Almaty 050040, Kazakhstan

\begin{abstract}
In this article, the "Qamqor" robotic system to provide employment for people with disabilities is developed. This system allows a person with disabilities to remotely control the "Ai-Gerim» robot, which performs service and other works at user institutions, while at home. The design of the social humanoid robot "Ai-Gerim" and the software modules of the "Qamqor" system have been developed.
\end{abstract}

Keywords: Robotic system;Social humanoid robot;Remote control

\section{Introduction}

Industrial robots have been used for a long time in many industries: in mechanical engineering, military-space industry, agriculture, etc. Since the 1990s, the development of service robots began, which do useful work for people, with the exception of industrial automation tasks, for example, robots - cleaners, robots - guides, robots-consultants. The development of service robots, in turn, led to the creation of social robots capable of social interactions with humans [1-9] for example, assistant - robots, companion robots, robots for rehabilitation. Robot - assistants, in addition to performing basic functions, carry out social interactions with a person to provide assistance. For example, the humanoid robot "AVA" of the company "i-robot" [10], except for cleaning the house, collects information about the medical condition of its owner and transmits this data to the attending physician, robot - warden of Asian Forum for Corrections group [11], except for observation of convicts, mediates between prisoners and wardens, the humanoid robot Octavia [12] interacts with fireFigurehters when extinguishing a fire, robot Robonaut 2 [13] works on the NASA international space station, interacting with astronauts. Robots for rehabilitation support the mental health of people, especially the elderly, through communication, and also involve people with disabilities in public life (work, study, communication). Widely known is the robot - the baby seal Paro [14], which perceives people and the environment, demonstrates joy when it is ironed. This causes a calming effect and positive emotions in older adults and hospital patients.According to the international work organization, about 650 million people on our planet are with disabilities. In some countries, up to $80 \%$ of people with disabilities are unemployed. This is a big problem, since this category of people breaks away from social life. One of the directions to solve this problem is to attract people with disabilities to work and public life with the help of remotely controlled social robots. Remote control of such social robots by operators - people with disabilities, being at home, on the one hand attracts them to work and public life, and on the other hand, reduces the cost of robots. It is known that the bulk of the cost of robots operating offline is their control systems, for example, the cost of autonomous service robots Rob thespian (UK), Pepper (Japan), SANBOT Max (China), Promobot V.4 (Russia) are respectively 86486 USD, 34189 USD, 28194 USD, 19134 USD.This paper describes the "Qamqor" robotic system for employing people with disabilities. This system is created on the basis of the cheap developed remotely controlled social humanoid robot "Ai-Gerim," which costs 3000 USD. 


\section{Qamqor System}

The Qamqor system includes the following objects (Figure1): b. Administrator.

c. User.

a. Operator.

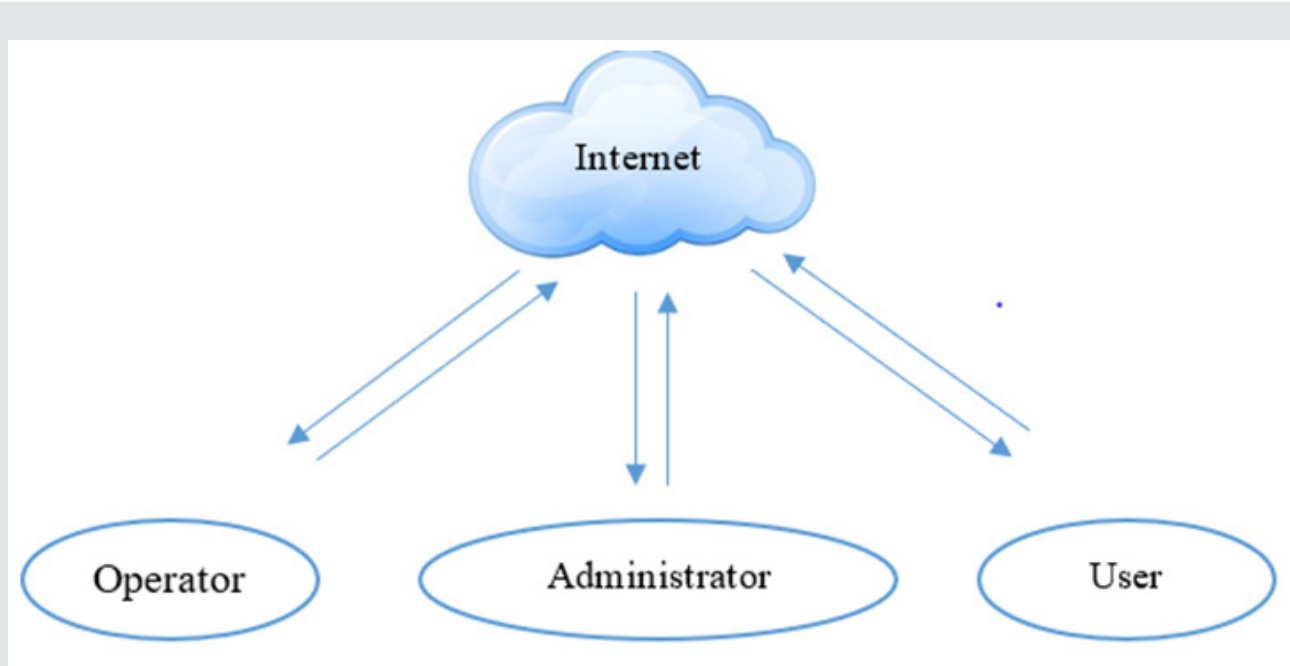

Figure 1: Objects of the "Qamqor" system.

The User is an institution (museum, supermarket, etc.) where the robot "Ai - Gerim" is used as a guide, consultant, etc. The robot is located in the User's institution, here tasks are issued and the quality of their implementation is checked, and payment is transferred to the Operator through the Administrator for the completed task. The Operator who is the person with disabilities, being at home, remotely controls the robot via the Internet to complete the User's task and receives payment through the Administrator. Interaction between the User, the Operator and the Administrator is carried out via the Internet.

The Administrator has two departments: a technical department and an information department with a server. The technical department deals with the technical support of robots and their serviceability. The information department is equipped with a program written in Python, the first page of which is shown in Figure 2. The "About us" pages contain information about the "Qamqor" system (Figure3), as well as technical characteristics (Figure 4), design (Figures 5\&6) and On the "User" page (Figure 7) the institutions where the robots "Ai - Gerim" will be used are registered and each User is automatically assigned a

Each User, by logging into his login, goes to the pages that contain the following pages:

1. "Personal account" (Figure 8). Here information about the User is presented, which can be changed. Changed information is also changed on the server.

2. "Tasks" (Figure 9) The types of tasks, place and time of their execution are indicated here. Each task has its own ID. The user can delete the task by his ID.

3. "Payment" (Figure 10)Here, the User pays for the completed task, which is carried out according to the available task ID and the Operator.

4. "Adding tasks" (Figure 11) Here the User can add new tasks. Added tasks are automatically entered into the list of User and Operator tasks.

5. "List of payments" (Figure 12) Here is a list of payments for completed tasks, indicating the Operator ID and the task.

6. "List of Operators" (Figure 13) Here is a list of all operators with their ID and personal details.

The Operator enters the first page of the "Qamqor" system and registers on the "Operator" page, receives his personal ID(Figure 14).

Each Operator, by entering his login, goes to the pages that contain the following pages:

1. "Personal account" (Figure 15) Provides information about the Operator that can be changed.

2. Tasks" (Figure 16) The types of tasks, locations and times of their execution are indicated here.

3. "Payment" (Figure17) The ID of the completed task and the amount of payment are 


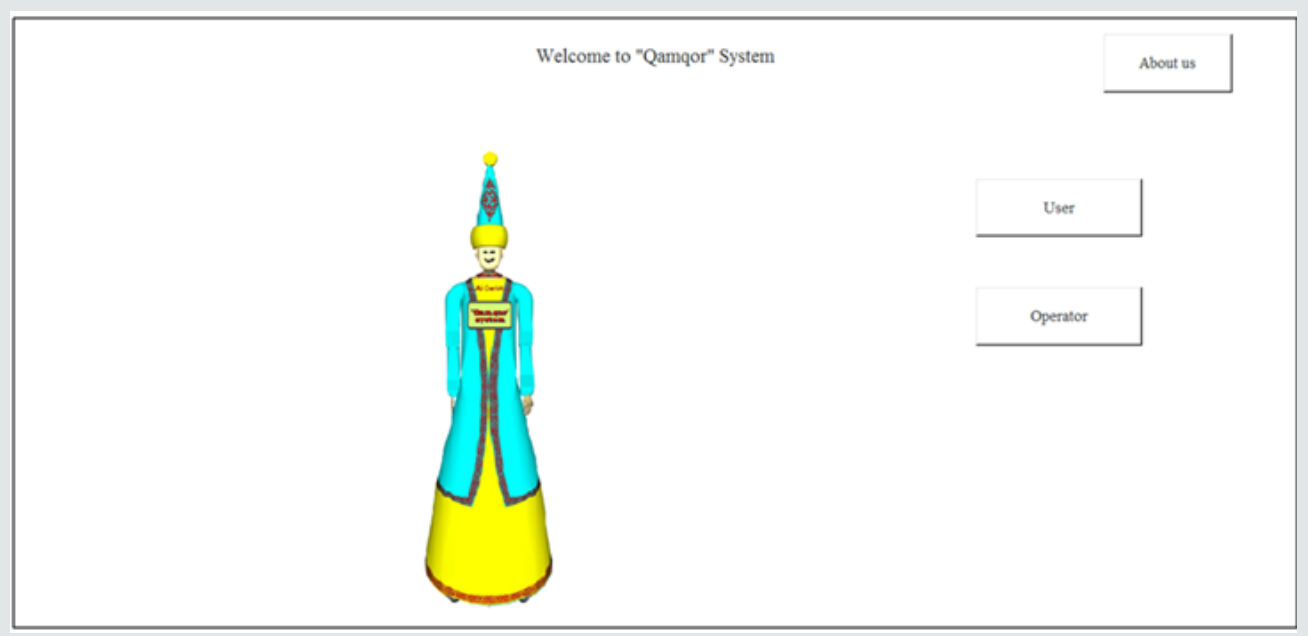

Figure 2: The main page of the "Qamqor" system.

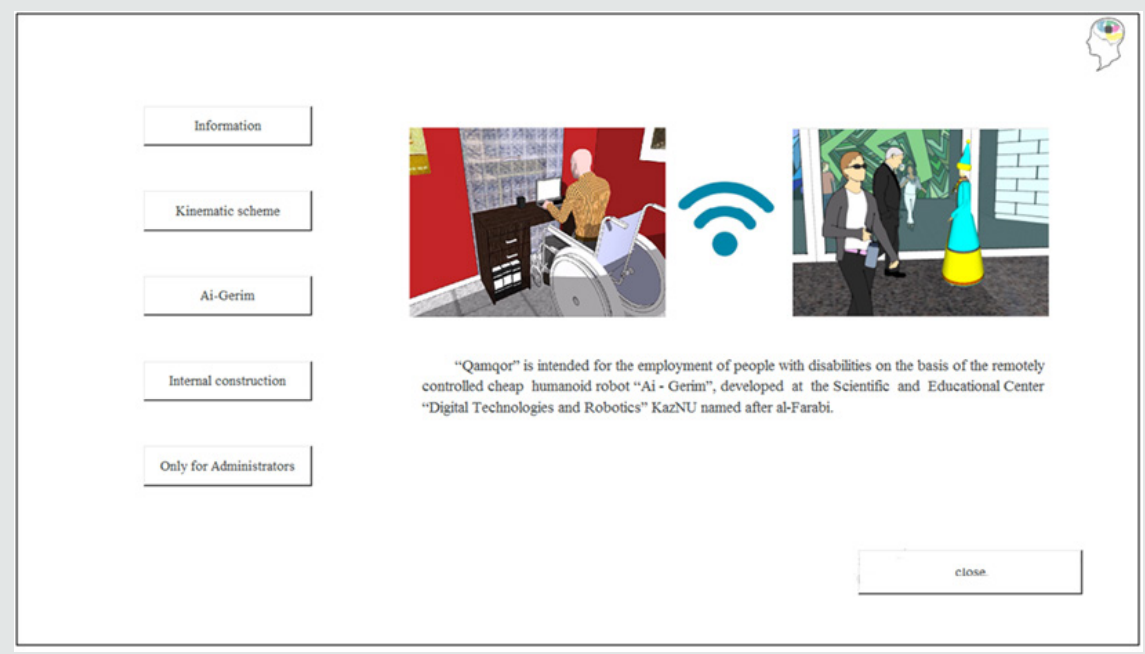

Figure 3: Information about the "Qamqor" system.

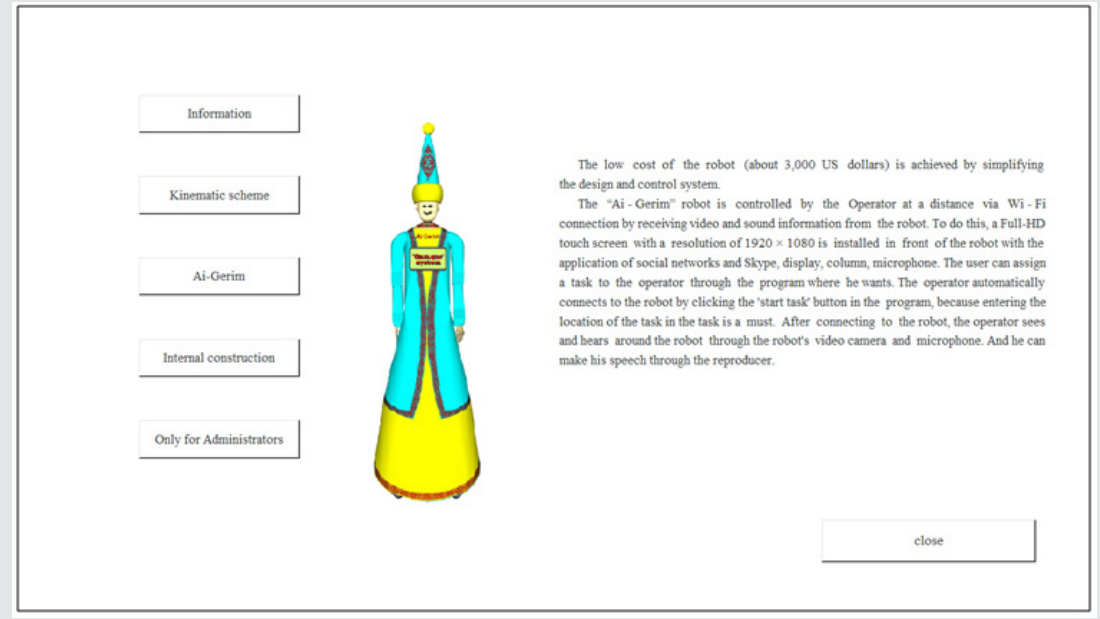

Figure 4: Technical characteristics of the robot "Ai - Gerim". 


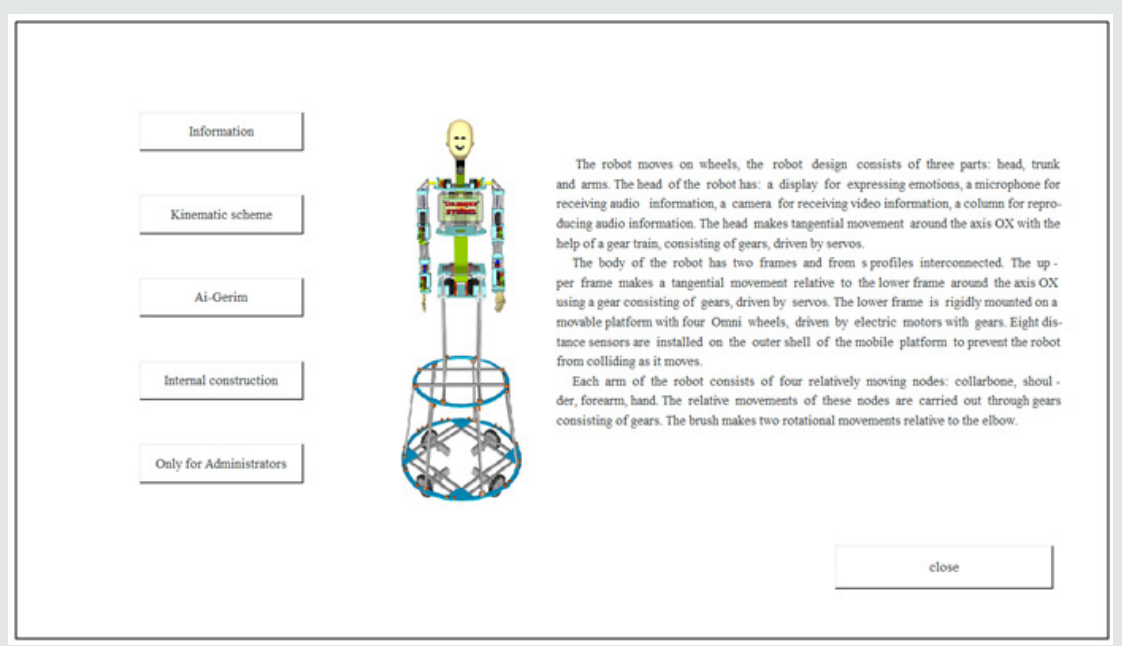

Figure 5: Construction of the robot "Ai - Gerim".

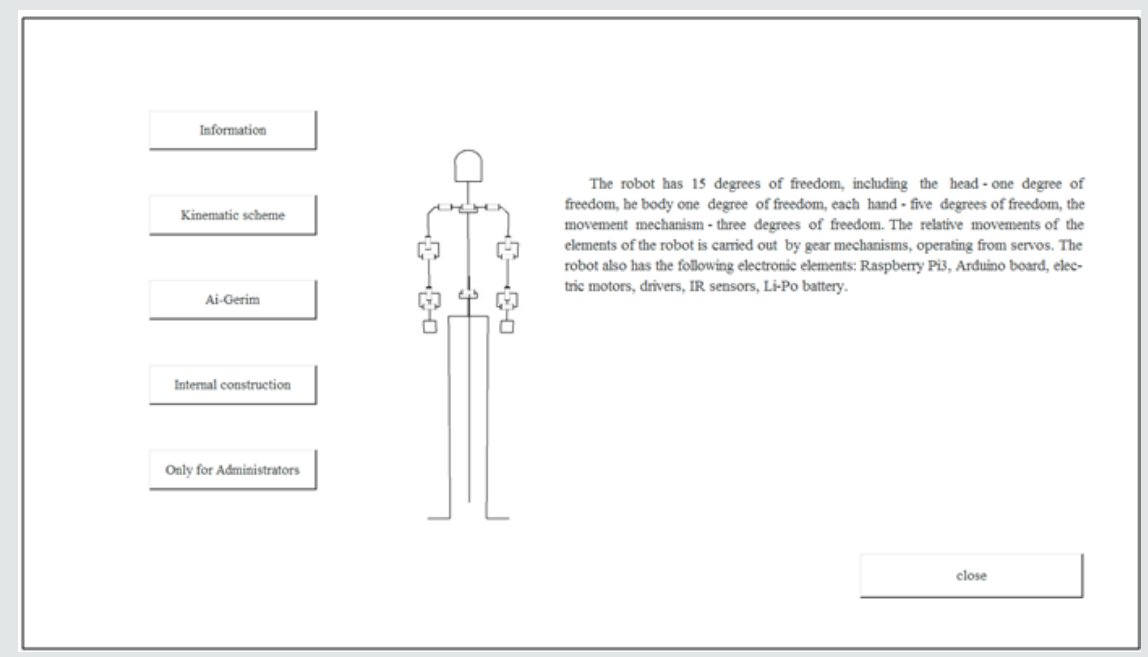

Figure 6: Kinematic diagram of the "Ai - Gerim" robot.

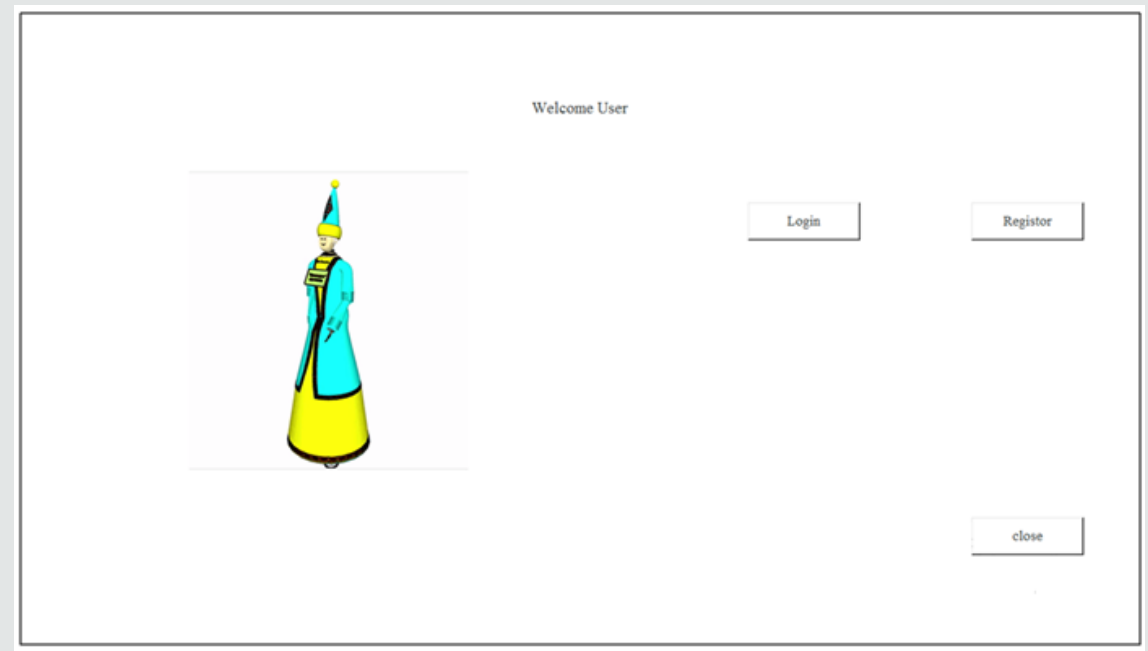

Figure 7: User home page. 


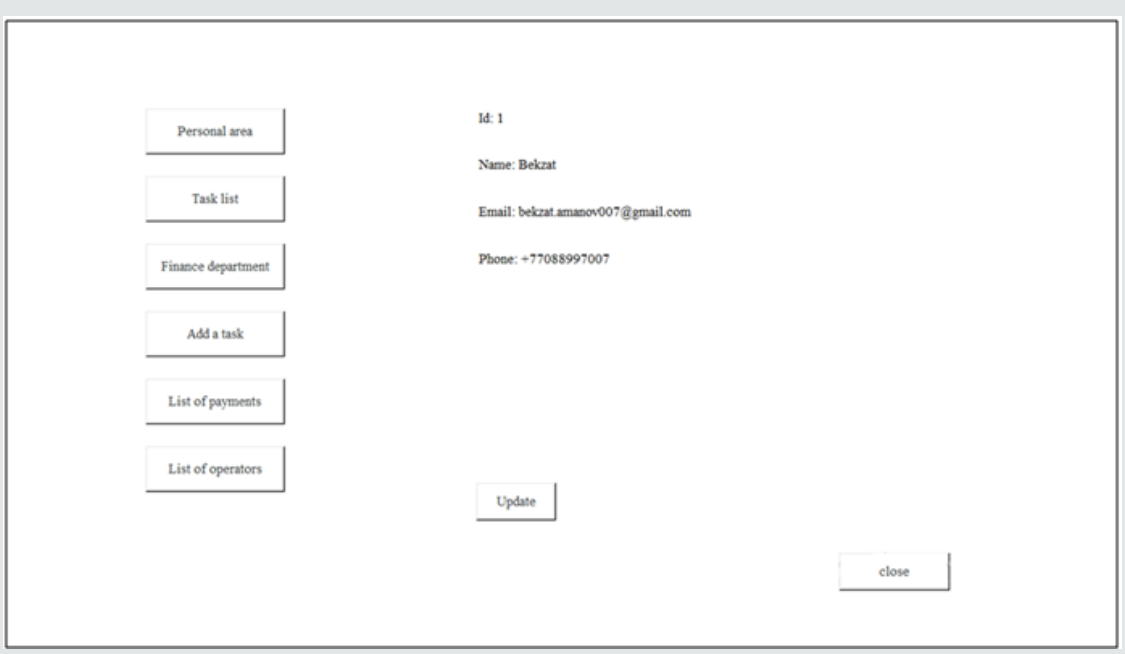

Figure 8: The "User's personal account" page.

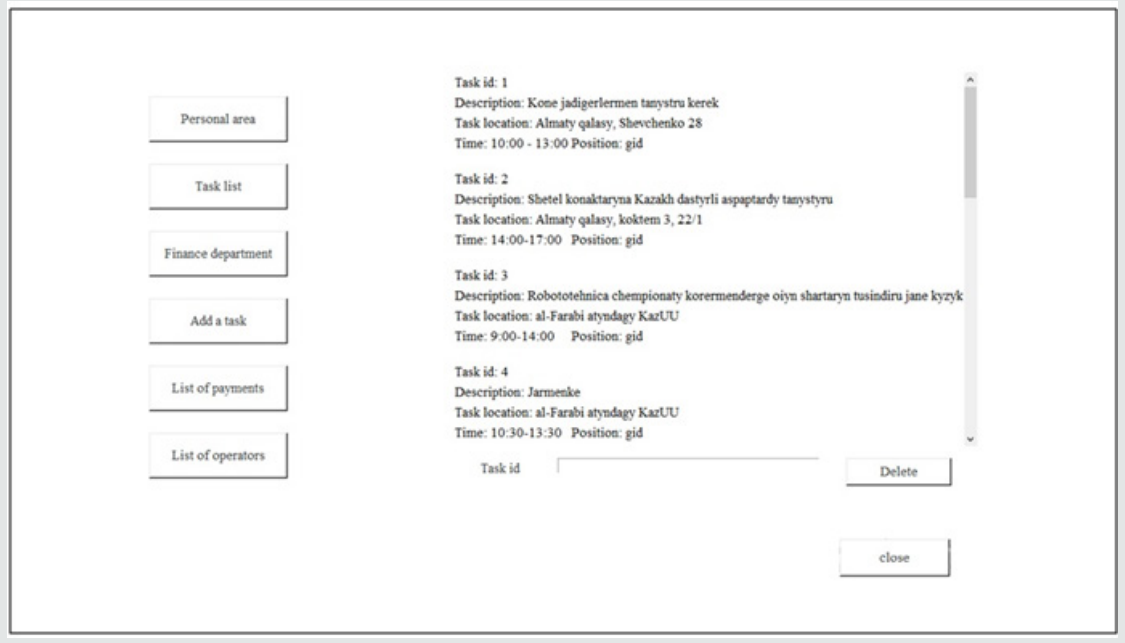

Figure 9: The "User jobs" page.

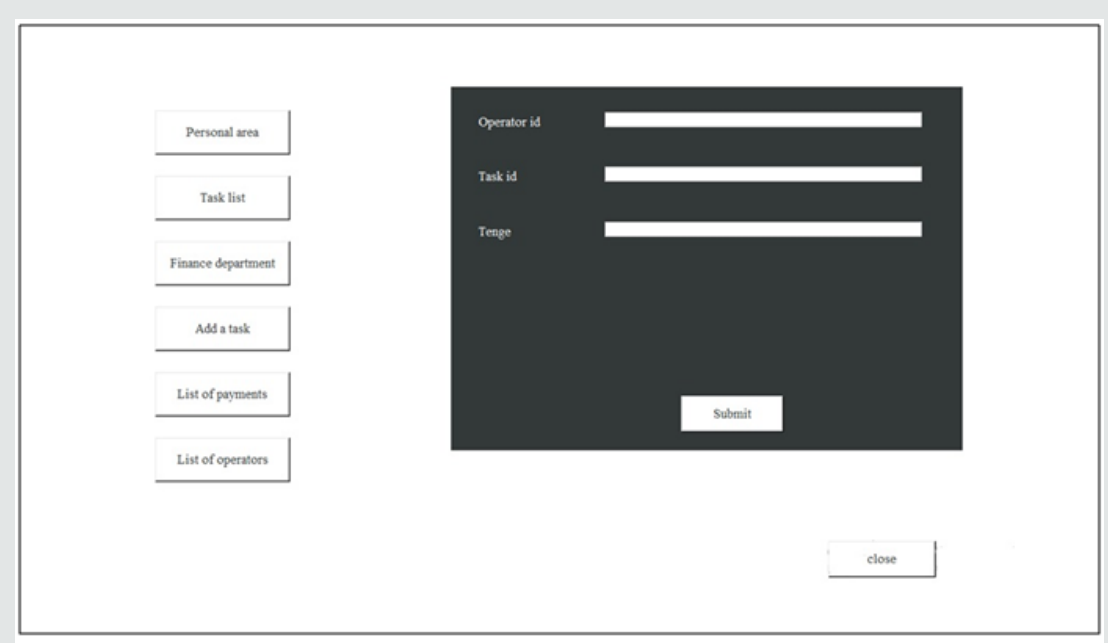

Figure 10: The "User payment" page. 


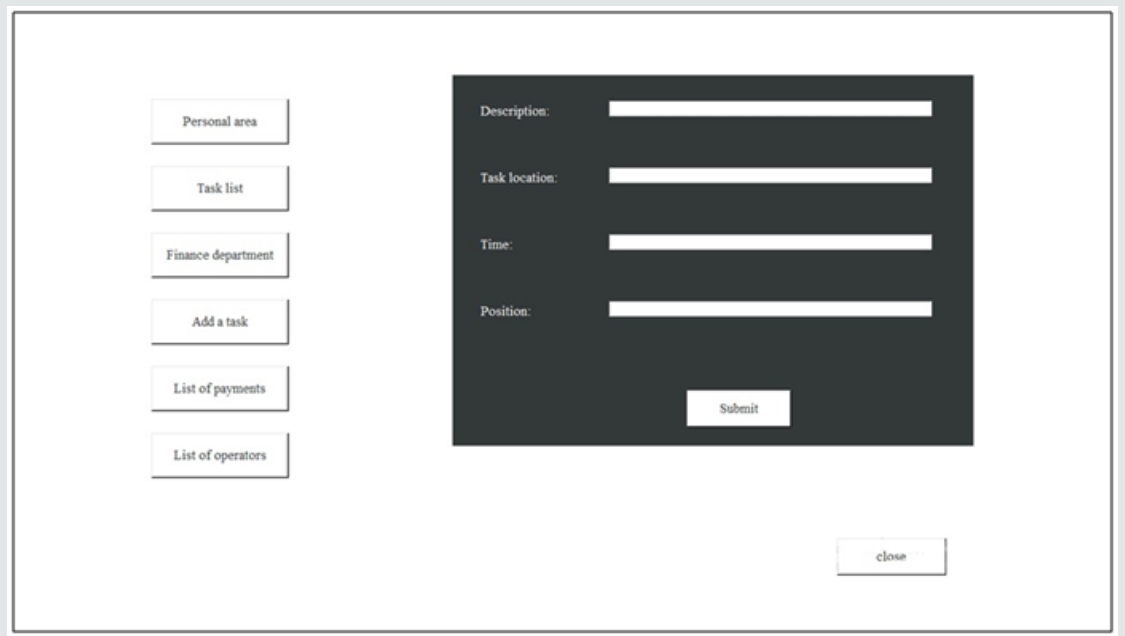

Figure 11: The "Add User jobs" page..

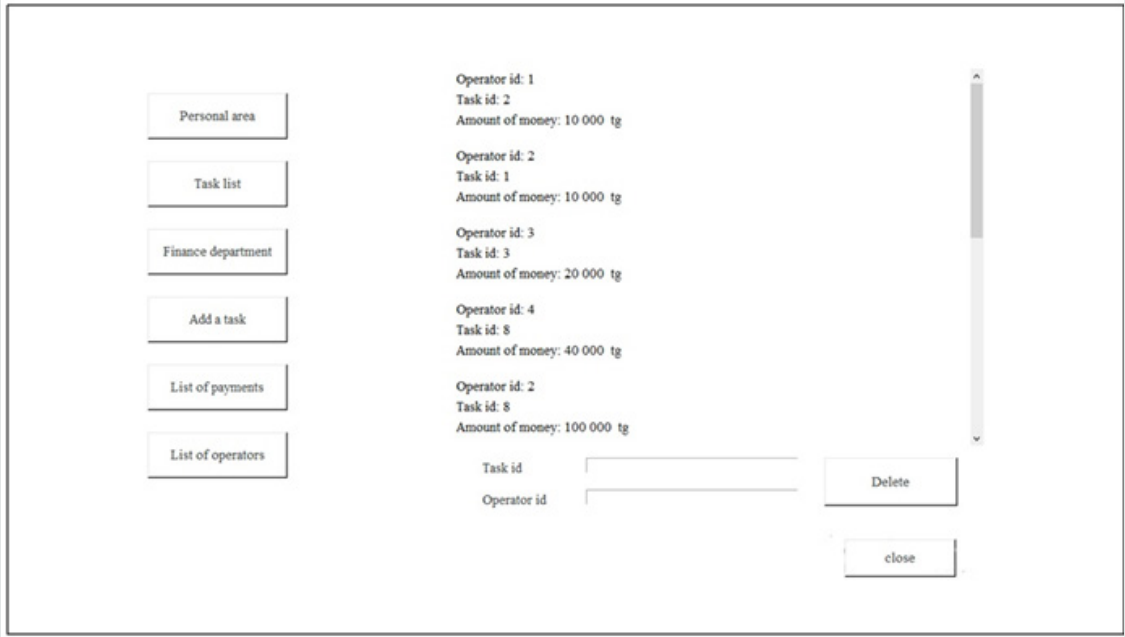

Figure 12: The "User's payment list" page.

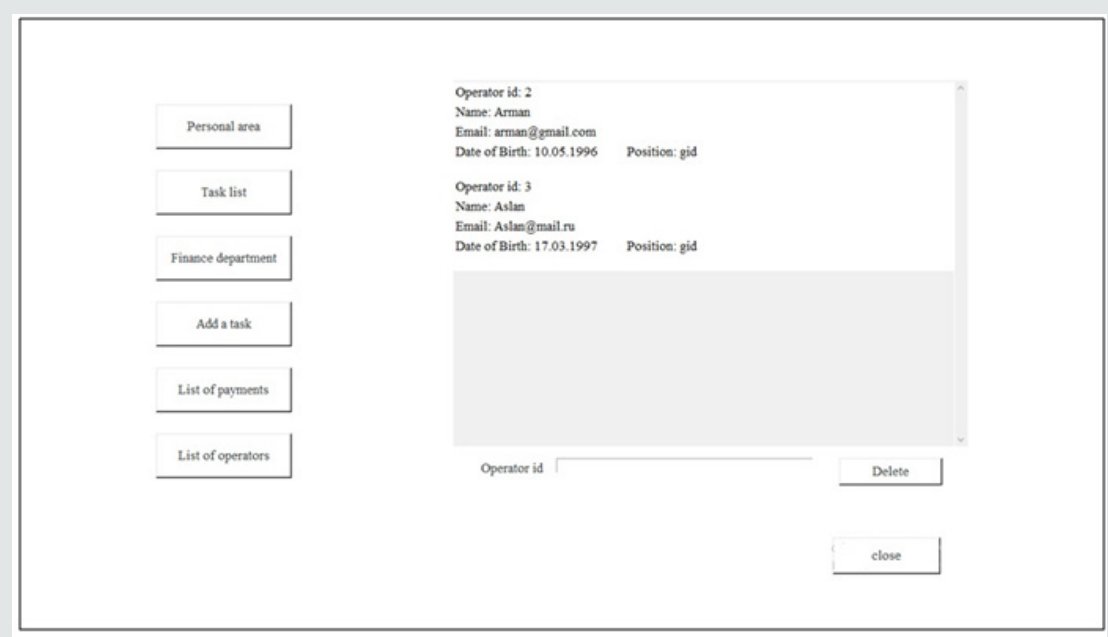

Figure 13: The "List of Operator's" page. 


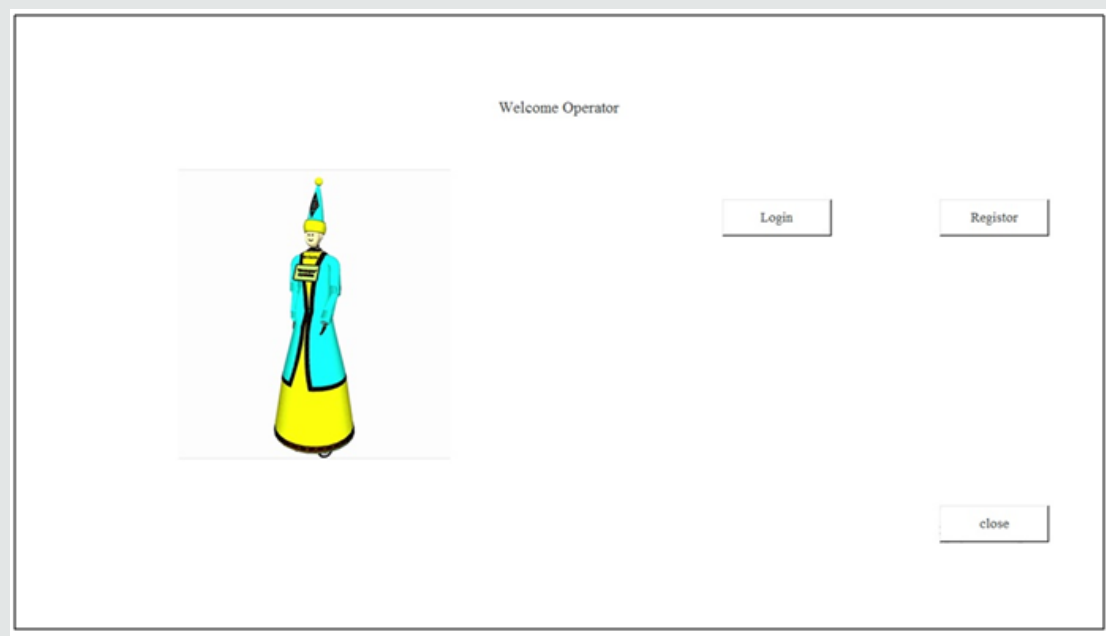

Figure 14: The "Operator's main page".

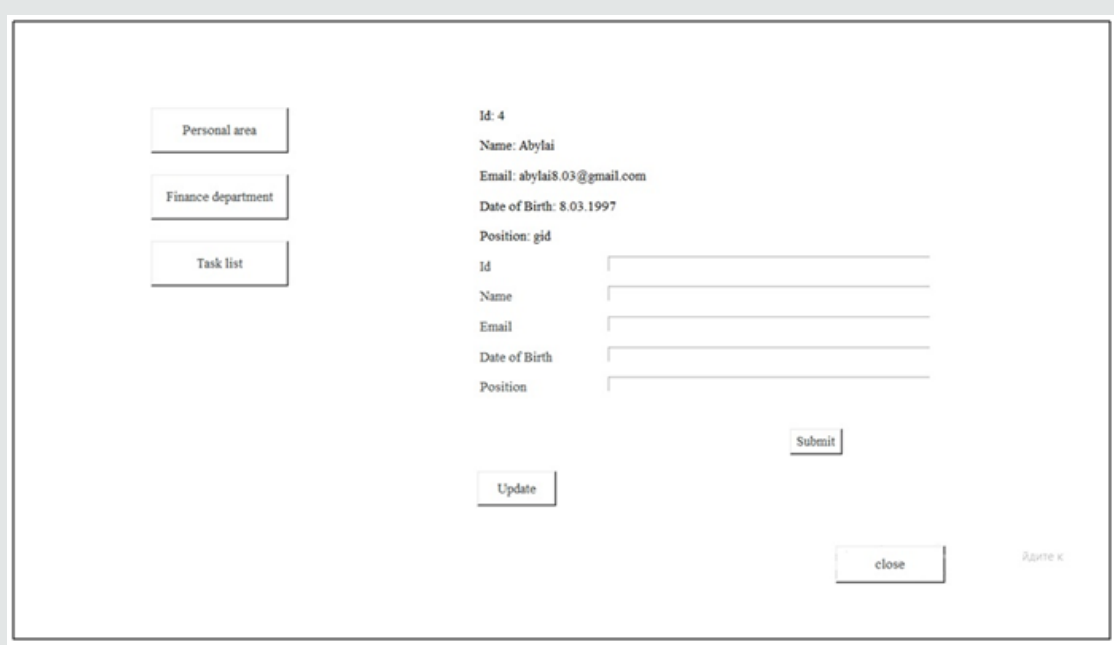

Figure 15: The "Operator's personal account" page.

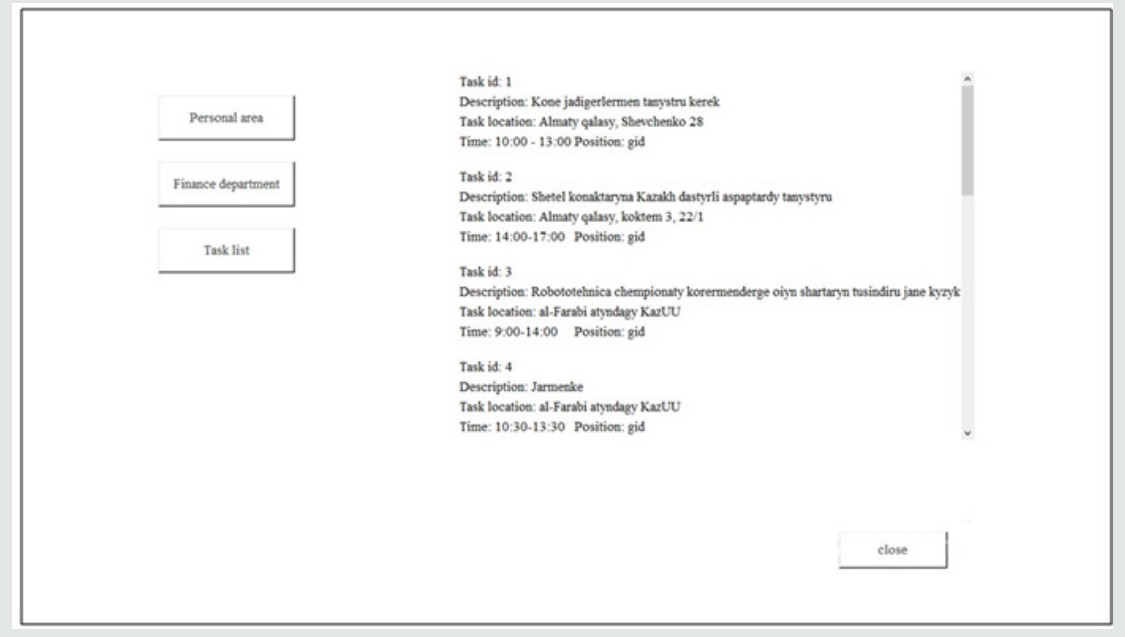

Figure 16: The "Operator jobs" page. 


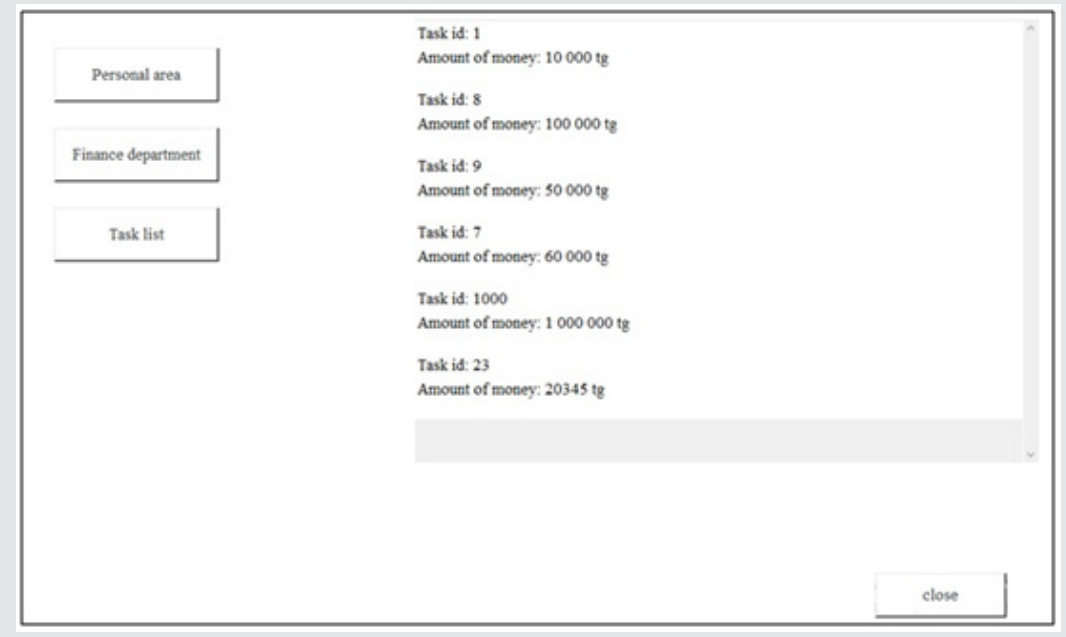

Figure 17: The "Operator payment" page.

Let's consider the work of the "Qamqor" system in the following example.

1. Let 10 "Ai-Gerim" robots be manufactured at the initial stage and provided to 10 Operators free of charge. Since the "Ai-Gerim" robot is a proprietary design and licenses are not required for their manufacture, and the cost of one robot is 3000 USD, the sum of manufacturing 10 robots is 3000 USD.

2. 10 Operators with robots "Ai-Gerim" areemployed by Users from home, with a monthly payment of 300 USD.

3. Each Operator uses 150 USD monthly for himself, and 150 USD is transferred to the Administrator's Accumulation Fund.

4. After 20 months, the amount of the Savings Fund is USD 30,000 .

5. Consequently, in 20 months the cost of ten robots will pay off or 10 new robots will be manufactured at the expense of theAccumulation Fund and 10 new Operators will be provided with work.

The relationship between the Operator, the User and the Administrator is carried out by the "Qamqor" system. With the help of this system, the Operator, while at home, by transmitting and receiving audio and video information, controls the robot "Ai Gerim" to perform the tasks of the User. For this purpose, in front of the robot, a Full HD touch screen with a resolution of $1920 \times 1080$ is installed with the application of social networks and Skype, a video camera, a display, a speaker, a microphone. Information about tasks, locations of their execution and payment is entered by the User into the system. The Administrator delivers the robot, through the system regulates the relationship between the User and the Operator, provides a service to improve the qualifications of the Operator.

\section{Conclusion}

The "Qamqor" robotic system uses a low-cost social humanoid robot "Ai - Gerim" to provide employment for people with disabilities. This robot is located at the user's premises, where it performs services and is remotely controlled by a disabled human operator while at home. Remotely controlled social robots are of great importance in the modern conditions of the coronavirus pandemic for the provision of non-contact medical and service services.

\section{References}

1. Hegel F (2009) Understanding Social Robots. Second International Conference on Advances in Computer-Human Interactions pp.169-174.

2. Duffy BR, Rooney C, O'Hare GM, O'Donoghe R (1999) What is a Social Robot? $10^{\text {th }}$ Irish Conference on Artifical Intelligence \& amp; Cognitive Science University College Cork Irland p. 96-118.

3. Young JE (2011) Evaluating Human-Robot Interacting. International Journal of Social Robots 3(1): 53-67.

4. Breazeal C (2004) Social Interactions in HRI: The Robot View. Systems, Man, and Cybernetics. Part C: Applications and Reviews 34(2): 143-166.

5. Fong I, Nourbakhsh I, Dautenkahn K (2003) A Survey of Socially Interactive Robots. Robotics and Automation Systems 42(3): 143-166.

6. Brazeal C (2003) Toward Sociable Robots. Robotics and Automation Systems 42(3):167-175.

7. De Graaf MMA, Alltouch SB, van Dijk J (2015) What Makes Robot Social? A User's Perspective on Characteristics for Social Human-Robot Interaction. Social Robotics pp. 184-193.

8. Engelhardt KG, Edwards RA (1992) Human robot Integration for Service Robotics. Human- Robot Interaction. London pp. 315-346.

9. Yang S (2015) Experiences Developing Socially Acceptable Interactions for a Robotic Trash Barrel. Robot and Human Interactive Communication (ROMAN), 24 ${ }^{\text {th }}$ IEEE International Symposium pp. 277-284.

10. AVA Overview Irobot.

11. Bloss R (2012) Robots Go to Prison-as Guards. An International Journal Industrial Robots 39: 148-158. 
12. Martinson E (2012) Fighting Fires with Human Robot Teams. IEEE / RSJ International Conference on Intelligent Robots and Systems pp. 2682 2683.

13. Diftler MA (2011) Robonaunt 2-The First Humanoid Robot in Space. Robotics and Automation (ICRA), IEEE International Conference pp. 2178-2183.
14. Sabanovis S (2013) Paro Robot Affects Divers Interaction Modalities in Group Sentory Therapy for Older Adult with Dementia. Rehabilitation Robotics (ICORR), IEEE International Conference p. 1-6.

\section{(c) (i) \\ This work is licensed under Creative Commons Attribution 4.0 License}

To Submit Your Article Click Here:

Submit Article

DOI: 10.32474/ARME.2020.02.000144

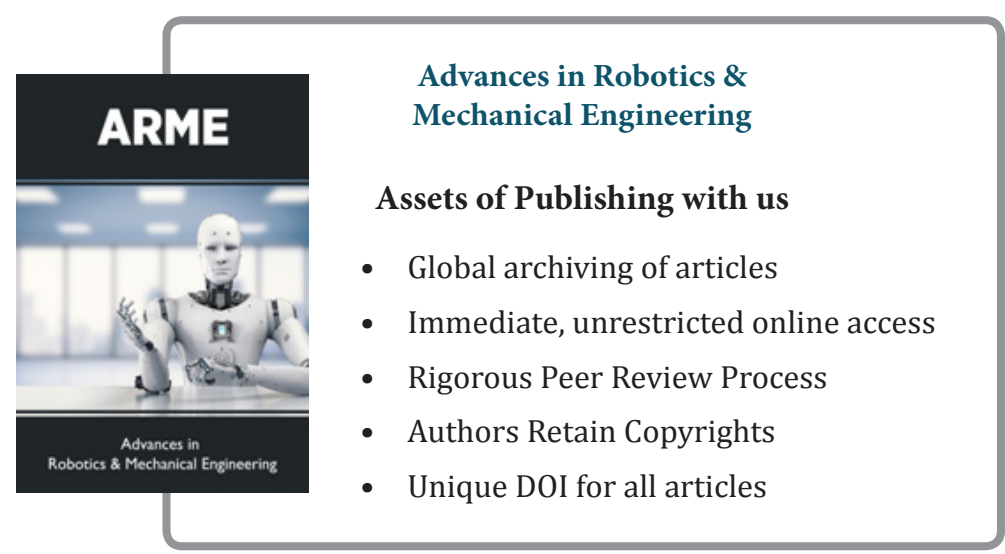

